\title{
MONTAGENS \\ VERBO-VISUAIS \\ E CHARGES NA \\ COMUNICAÇÃO POLÍTICA: \\ A DERRISÃO DISCURSIVA \\ SOBRE MICHEL TEMER, \\ O USURPADOR
}

\begin{abstract}
MONTAGES VERBO-VISUELS ET CARICATURES DANS LA COMMUNICATION POLITIQUE: LA DÉRISION DISCURSIVE DE MICHEL TEMER, L'USURPATEUR
\end{abstract}

VERBAL AND VISUAL MOUNTS AND CHARGES IN POLITICAL COMMUNICATION: THE DISCURSIVE DERISION ABOUT MICHEL TEMER, THE USURPER

Samuel Ponsoni*

Universidade do Estado de Minas Gerais

\begin{abstract}
RESUMO: Este artigo tem como objetivo analisar dois percursos discursivos de sentido produzidos por meio de montagens verbo-visuais e charges acerca do ex-presidente, Michel Temer (2016-2018), representado pela figura do usurpador. Esses percursos nos mostram um conjunto temático-discursivo de sentidos que oscilam entre Temer, um usurpador golpista e um usurpador autoritário. Nesse aspecto, nosso trabalho se fundamenta nos pressupostos da Análise do Discurso de matriz francesa e, mais especificamente, na noção-conceito de Derrisão (BONNAFOUS, 2003;MERCIER, 2001; BARONAS, 2005, 2008), com base na qual buscamos refletir sobre como essa forma de discurso humorístico de desvalorização e satirização agressiva produz embates discursivos com o outro discursivo, sobretudo na esfera da comunicação política. Portanto, responder a essa questão teórica e analiticamente faz parte dos objetivosdeste texto.
\end{abstract}

PALAVRAS-CHAVE: Comunicação política. Derrisão. Discursos verbo-visuais.

RÉSUMÉ: Cet article vise à analyser deux parcours discursifs de sens produits au moyen de montages verbo-visuels et de caricatures sur l'ancien président, Michel Temer (2016-2018), le représentant la figure de l'usurpateur. Ces parcours nous montrent un ensemble de significations thématiques-discursives qui oscillent entre Temer, usurpateur de coup d'État et

*Professorda UniversidadedoEstadode Minas Gerais-UEMG UnidadePassos. E-mail: samuel.ponsoni@uemg.br 
usurpateur autoritaire. Dans cet aspect, notre travail est fondé sur les hypothèses de l'Analyse matricielle du discours français et, plus spécifiquement, sur la notion-concept de dérision (BONNAFOUS, 2003; MERCIER, 2001; BARONAS, 2005, 2008), à partir de laquelle nous réfléchissons sur la manière dont cette forme de discours humoristique de dévalorisation et de satirisation agressive produit des heurts discursifs avec l'autre discursif, notamment dans la sphère de la communication politique. Par conséquent, répondre à cette question de manière théorique et analytique fait partie des objectifs de ce texte. MOTS CLÉS: Communication politique. Dérision. Discours verbo-visuel.

ABSTRACT: This article aims to analyze the two paths of meaning of discourses produced by means subjects of verbs and visual montages and charges about the former president, Michel Temer (2016-2018), representing him as a usurper. These paths show us a thematic and discoursive set of meanings that oscillate between a usurper who is a coup plotter and an authoritarian usurper. In this aspect, our work is projected from the assumptions of the French Discourse Analysis, with which we seek, in the notionconcept of Derision (BONNAFOUS, 2003; MERCIER, 2001; BARONAS, 2005, 2008), ways to reflect upon how this form of humorous discourse of devaluation and satirizing aggressive produces discursive clashes with the other discursive especially in the sphere of political communication. Therefore, answering these questions theoretically and analytically is part of the objectives of this text.

KEYWORDS: Political communication. Derision. Verbal and visual discourses.

\section{QUESTÕES INICIAIS}

A palavra usurpador em sentido vernacular, significa comumente que ou aquele que usurpa; que se apodera ilicitamente, por vezes com violência, por vezes com artifícios e ardis, daquilo que não lhe pertence ou a que não tem direito. Deste sentido mais vernacular, tem-se, em léxico corrente, no campo político, aquele sujeito que toma de maneira ilítica o poder político, institucional e constituído em determinadas sociedades, em certas quadras históricas. Ainda no campo político, atribui-se ao já falecido e histórico político brasileiro, Leonel de Moura Brizola (1922-2004), aliás, um exímio frasista, uma frase que diz muito sobre como a usurpa e o usurpador são vistos no campo político. Dizia o finado político gaúcho, em distintas paráfrases, que "a política ama a traição e odeia o traidor". Os artifícios de usurpa são vistos, portanto, como um ato de traição, relegando ao traidor o rés do chão em termos de avaliação dos pares no campo político.

Neste sentido, o trabalho ora aqui tratado se propõe a perquirir dois pequenos percursos de sentido de discursos produzidos no fenômeno de linguagem e interação de comunicações construídas por meio de um tema, a usurpa, em montagens verbovisuais e charges. Esse gesto não se dará de qualquer maneira, mas sim na relação entre a produção e circulação dessas montagens e charges na comunicação política por meio dos discursos envoltos à figura do brevíssimo e contestado expresidente brasileiro, Michel Temer (2016-2018).

Dessa forma, nosso trabalho se projeta nos pressupostos da Análise do Discurso de matriz francesa, com os quais buscamos, mais especificamente por meio da noção-conceito de Derrisão discursiva (BONNAFOUS, 2003; MERCIER, 2001; BARONAS, 2005, 2008), maneiras de compreender e refletir sobre como essa forma de discurso humorístico de desvalorização e satirização mais agressiva produz embates discursivos com o outro discursivo. Isto é, como e o quê, por meio da derrisão, se dá na formulação do tom humorístico político em percursos em relação ao outro objeto de embate discursivo.

Para isso, trabalharemos com montagens verbo-visuais e charges que buscam tornar, em forma derrisória discursiva, o ator político Michel Temer em um percurso temático de sentido no qual ele figura como um usurpador do poder, a partir de determinados acontecimentos históricos, como, por exemplo: o período pós-ascensão à presidência, 2017, e ao poder políticoinstitucional pelo discutivel impeachement ou golpe contra a ex-presidenta Dilma Rousseff, que se deu oficialmente em agosto de 2016; os acontecimentos da Intervenção Militar no Rio de Janeiro, fevereiro de 2018 e do desfile da Escola de Samba Tuiuti, também em fevereiro de 2018, que caracterizaram o ex-mesoclítico presidente como Vampiro. Ademais, as análises que recobrem este trabalho como espécies de recortes de parte pelo todo se dão, como dissemos alhures, em dois (02) percursos 
derrisórios tematizados no discurso visual e no discurso verbal, derivados desses acontecimentos: 1) Temer, o usurpador de um golpe; 2) Temer, o usurpador autoritário.

Portanto, o objetivo principal deste artigo é apontar caminhos teóricos e analíticos, com os domínios epistemológicos da Análise de Discurso francesa, na esfera de atividade da comunicação política, para a compreensão de um dos fenômenos discursivos de linguagem, que é a derrisão, ao ser utilizada como zombaria do discurso outro político, existindo por meio de certos gênero discursivos das esferas de atividades sociais da internet.

Antes de prosseguir, cumpre dizer que compreendemos os gêneros montagens verbo-visual e charge aqui mobilizados na esteira de Mikhail Bakhtin (1997). Ele define que as bases de constituição da linguagem estão nos enunciados concretos construídos dialogicamente na comunicação e interação entre os sujeitos e a realidade social em que eles vivem. São enunciados ancorados em gêneros do discurso, os quais se apresentam sob três constituintes básicos: conteúdo temático, estilo e construção composicional. As três bases constituintes "[...] fundem-se indissoluvelmente no todo do enunciado, e todos eles são marcados pela especificidade de uma esfera de comunicação” (BAKHTIN, 1997, p. 280). E o pensador russo continua:

Todas as esferas da atividade humana, por mais variadas que sejam, estão sempre relacionadas com a utilização da língua. Não é de surpreender que o caráter e os modos dessa utilização sejam tão variados como as próprias esferas da atividade humana, o que não contradiz a unidade nacional de uma língua. A utilização da língua efetua-se em forma de enunciados (orais e escritos), concretos e únicos, que emanam dos integrantes duma ou doutra esfera da atividade humana. O enunciado reflete as condições específicas e as finalidades de cada uma dessas esferas, não só por seu conteúdo (temático) e por seu estilo verbal, ou seja, pela seleção operada nos recursos da língua - recursos lexicais, fraseológicos e gramaticais -, mas também, e, sobretudo por sua construção composicional. Estes três elementos (conteúdo temático, estilo e construção composicional) fundem-se indissoluvelmente no todo do enunciado, e todos eles são marcados pela especificidade de uma esfera de comunicação. Qualquer enunciado considerado isoladamente é, claro, individual, mas cada esfera de utilização da língua elabora seus tipos relativamente estáveis de enunciados, sendo isso que denominamos gêneros do discurso. (BAKHTIN, 1997, p. 280)

Como se vê pela citação do filósofo russo, há permanente caráter dialógico da relação entre indivíduos de um dado grupo, ou comunidade semiótica, ao dizer de Bakhtin, e isso é determinante para promulgação de diversos tipos e formas de gêneros, tanto orais quanto escritos.

Cumpre ainda dizer que, para compor os recortes de análises, utilizamos os discursos dos mais distintos dispositivos comunicativos (mídiuns, pela terminologia de Dominique Maingueneau, 2008, 2015), como as redes sociais e sites, que nos deram os objetos discursivos de comunicação política acerca do ator político Michel Temer em acontecimentos que desencadearam e circularam uma série de efeitos de sentido sobre esses acontecimentos.

Essa forma pluritópica de se buscar objetos de análise e pesquisa para formar um corpus de pesquisa se alinha ao que Dominique Maingueneau (2006) vai chamar de um corpus de unidades tópicas e de unidades não tópicas, em que vale o percurso dos discursos e das formações sociais que utilizam esses discursos.

Podem-se também considerar os percursos de tipo formal(por exemplo, tal tipo de metáfora, tal forma de discurso relatado, de derivação sufixal...); mas, nesse caso, não se trabalha sobre um conjunto discursivo bem especificado( em particular um gênero de discurso ou um posicionamento), cai-se em uma análise puramente linguística. Podem-se igualmente considerar percursos fundados sobre materiais lexicais ou textuais( por exemplo, a retomada ou as transformações de uma mesma fórmula em uma série de textos, ou ainda as diversas recontextualizações de um "mesmo texto"). É assim que um trabalho foi desenvolvido sob a fórmula "depuração étnica"(Krieg-Planque, 2003); trata-se, antes de tudo, de explorar uma dispersão, uma circulação, e não de relacionar uma sequência verbal a uma fonte enunciativa. (MAINGUENEAU, 2006, p. 21) 
Vemos pela citação que há uma série de percursos temáticos ou teóricos que podem ser buscados para se compor um corpus de pesquisa do artigo, prática essa que facilita bastante a conformação de um arquivo virtual, como é o nosso caso, pois não se depende exclusivamente de uma fonte física e analógica e nos ajuda a criar um percurso temático.

\section{2 (ALGUMAS) QUESTÕES SOBRE A DERRISÃO DISCURSIVA}

Pode-se dizer que a repercussão e a circulação da comunicação política podem reforçar um dado acontecimento, dando-lhe materialidade na repetição para que ele dure e "pegue" em uma nova regularidade do discurso e entre na ordem do dia dos rumores públicos, formando estruturas de múltiplas coerções projetadas, elementos decisivos para os percursos de interpretação dos sentidos (PÊCHEUX, 2008). Teoricamente mais específicos, podemos, neste trabalho, pensar o conceito de derrisão discursiva, no processo de compreensão dos montagens verbo-visuais e charges, como uma investida de buscar outros objetos de análise, dentro da seara do discurso político.

O conceito de derrisão vem há alguns anos recebendo diversas tentativas de compreensão científica, quer seja como um gênero textual-discursivo, verbal, não verbal, ou verbo-visual, quer seja como um tipo específico de discurso humorístico, muito caracterizado por sua utilização política, sobretudo nos chamados ciberespaços, mas, de qualquer perspectiva, a derrisão é tomada como um fenômeno discursivo da linguagem, como observam Bonnafous (2003) e Baronas (2005, 2008). A derrisão tem sentidos ligados à ordem de zombarias, escárnios, troças, que circulam em diversos campos, não somente no político, mas inclusive no campo religioso, sendo retratada na própria bíblia cristã, com as zombarias e escárnios produzidos em relação ao Cristo Messias'.

Nos trabalhos mais amplos teoricamente sobre derrisão ${ }^{2}$, evidencia-se que o mais fundamental para tal noção-conceito é contestar valores sociais em determinados momentos sócio-históricos. Definida como o ato de enfatizar os defeitos e deformidades do alvo escolhido, a derrisão se caracteriza como o humor que desqualifica o adversário no intuito de persuadir o auditório.

De modo mais específico em relação ao entendimento da derrisão, e que nos interessa mais neste artigo, temos as interpretações de uma das autoras que buscam pensar do ponto de vista discursivo o conceito de derrisão: Simone Bonnafous. Pelas perspectivas teóricas de Bonnafous (2003), derrisão, como noção-conceito discursiva, trata-se de associar humor com certa agressividade, que a caracteriza e a distingue da injúria. A derrisão tem como objetivo a subtração de qualquer valoração e valorização positiva dos objetos derrisados, ou seja, uma espécie de riso que desvaloriza o outro, sob qualquer situação ou aspecto. Assim, o que mais interessa na derrisão é estudar essa contestação de valores que circulam em determinado momento sócio-histórico, criando formas caricatas de junção de textos e discursos nos próprios gêneros verbovisuais.

Ainda sobre isso, mas com base em uma análise que avança em outra perspectiva, Mercier (2001) trata da derrisão como formas de inversão simbólica e temporária da ordem política, pois é um recurso discursivo capaz de associar perspectivas de resistências sociais e individuais ensejando uma espécie de dialética entre contestação, resistência, desobediência e regulação.

Por um lado, no engendramento do discurso de resistências, a derrisão é um fenômeno de linguagem que se utiliza de uma violência simbólica, que se manifesta tanto de forma verbal quanto não verbal ou sincrética, a depender do gênero em que

\footnotetext{
1 "O Escárnio de Cristo", pintura renascentista, de autoria do pintor Cenni di Petro Cimabué, considerado um mestre do Renascimento, mostra Jesus sendo zombado por uma horda de homens. Essa é uma das mais famosas obras pictóricas a retrar o tema de escárnio em torno da figura de Cristo, porém, há diversas outras obras honônimas, de pintores diferentes.

${ }^{2}$ Há um número completo da Revista Hermès que traz uma espécie de dossiê científico acerca do conceito, o qual foi chamado de Dérision-Contestation, organizado e coordenado por Arnaud Mercier, trabalhos esses que buscam o conceito e o trazem a uma reflexão disciplinar e científica (HERMÉS, 2001).
} 
está mobilizada, com questionamentos mais violentos que possam surgir dos poderes objetados, ou, de maneira mais sutil, irônica ${ }^{3}$, com uma bricolagem e fragmentação discursiva, ou seja, um recurso criativo para incidir contra as convenções. Por outro lado, no engendramento discursivo de regulação, ela pode, ao ser tolerada e controlada pelas estruturas de poder, contribuir para a eternização dos sistemas de dominação, de seus valores e códigos culturais.

Assim sendo, as formas de utilização do recurso discursivo derrisório são formasde liberar, de maneira socialmente aceitável, ainda que seja em uma cibercultura, um princípio de prazer transgressor tolerável. Portanto, tornar algo em derrisão, em riso escárnico, é um meio de liberar aquela agressividade contida, supostamente inexprimível, daquilo que está socialmente contigenciado por diversos processos de interdição, isto é, do cultural e linguístico, passando pela psicologia de massas, até os expedientes jurídicos.

Esse elemento de liberar e trazer alguma forma derrisória socialmente sustentável, que busca contornar algumas interdições, como dissemos, encontra terreno fértil em charges e montagens visuais, por serem formas discursivas historicamente possíveis a transgredir aquilo ou aqueles que estariam, em alguma medida, protegidos por um certo manto de legalidade institucional, como um presidente da República, por exemplo. Todavia, para que essa forma derrisória "cole" e se faça possível em um certo percurso de sentido, é preciso que existam condições históricas em dada conjuntura e uma personagem a ser objeto da derrisão que emane ou emule traços significativos para o rebatimento no corpo social. Dito de outra forma, havia no entendimento social a desconfiança da trama de uma usurpação por parte do vice, o primeiro suspeito em uma república presidencialista, pois entende-se que o cargo é o caminho mais "fácil" de se eleger indiretamente. Conspirações, ardis, armações, tramas, todo esse imaginário estava presente na assunção de Temer à presidência, de modo que é mais plausível que a troça, em derrisão, colocasse-o como alvo predileto da zombaria derrisória, na esteira do que tratam as referências teóricas aqui citadas, algo que iremos analisar mais à frente, enquanto características de discursos verbo-visuais.

É igualmente importante ressaltar que a derrisão não é, contudo, necessariamente uma forma de ironia. Ela se diferencia do discurso de humor produzido nos efeitos da ironia, uma vez o sujeito-enunciador assume o que diz no seu próprio discurso quando tem por objetivo desqualificar o destinatário:

[...] enquanto locutor da ironia coloca em cena um enunciador, cuja alocução não pode assumir explicitamente, deixando essa responsabilidade para o seu destinatário, o locutor da derrisão assume o que diz, contudo os efeitos do seu dizer são atenuados ora pelo efeito de escárnio que provoca, ora pela mobilização de um discurso Outro já legitimado na sociedade. (BARONAS, 2008, p. 147)

Como se vê pela citação do professor e pesquisador brasileiro Roberto Baronas (2008), o trabalho de derrisão é bastante ligado à desqualificação de um Outro constituído, específico da conjuntura e das condições de produção dos acontecimentos a que se referem. Dito de outro modo, a derrisão se difere da ironia por meio do que é assumido e não somente pelo locutor. O locutor da derrisão assume a sua materialidade linguística e tem o objetivo de desqualificar o destinatário, assim os efeitos ao assumir o seu dizer são atenuados como escárnio ou pela mobilização de um discurso que já foi legitimado na sociedade. Já o locutor da ironia coloca um enunciador em cena e não assume explicitamente, deixando essa responsabilidade para o seu destinatário. Mas é no campo político de disputas ideológicas e contradições, de todos os tipos, campo em que há uma série de "alvos", os quais têm se tornando cada vez mais objeto da derrisão popular que libera sua agressividade, utilizando-se dos recursos de derrisão ${ }^{4}$, que incidem nossas análises. Manifestar-se discursivamente por meio da derrisão é, portanto, uma maneira de se afirmar contra uma série de elementos políticos, no caso, a fim de debochar sobre outra coisa, sobre uma visão renovada, sobre uma criação diferente.

\footnotetext{
${ }^{3}$ Diríamos mais especificamente com tons de ironia, com uma encenação textual-discursiva de ironia.

${ }^{4}$ No Império e na Primeira e Segunda República, as charges políticas, o humor derrisório, a caricaturização dos políticos foi algo muito frequente. Angelo Augostini, com sua Revista Illustrada, utilizou-se da zombaria, sátiras e caricaturas para contradizer os discursos políticos de então. Cf. Lima (2017).
} 


\section{PERCURSOS TEMATIZADOS EM ANÁLISES}

Para este artigo, selecionamos duas montagens verbo-visuais e duas charges, representativas do fenômeno da derrisão discursiva, sobretudo com êfanse no visual das imagens mêmicas, para fazer o processo descritivo e interpretativo de Michel Pêcheux (2008). A escolha desses quatro objetos discursivos de análise se justifica, ainda, uma vez que neste artigo se estrutura na necessidade de compreender o fenômeno de linguagem das derrisões, da perspectiva discursiva, a partir de certos acontecimentos históricos ligados ao campo político. Por isso mesmo, de acontecimentos que vão desde a pós-ascensão ao poder, passando pela intervenção, até as declarações mentirosas em relação às situações sociais e econômicas do Brasil, divididos, como dissemos antes, em dois percursos, cujo tema é a usurpa. A seguir apresentamos o percurso 1: Temer, o usurpador de um golpe.

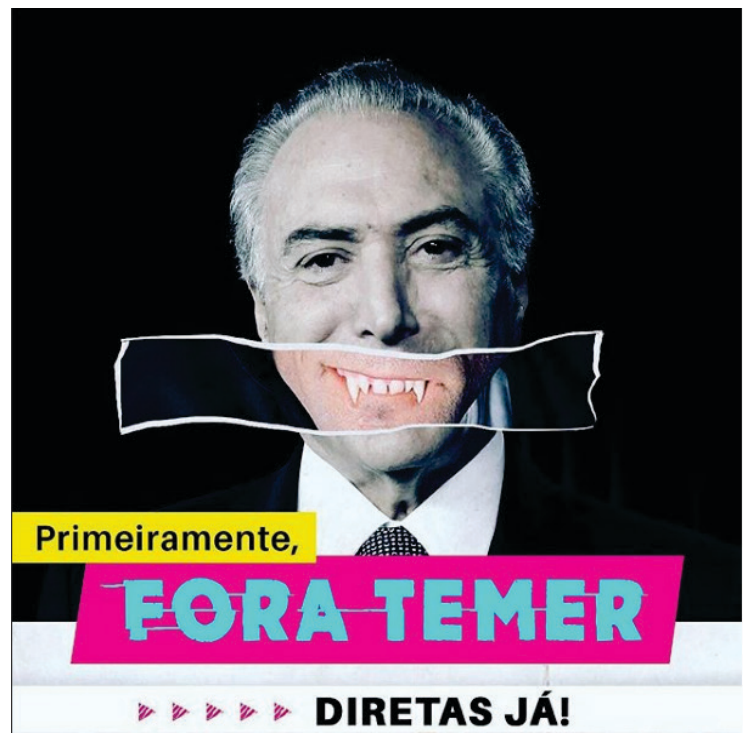

DIRETAS JÁ!

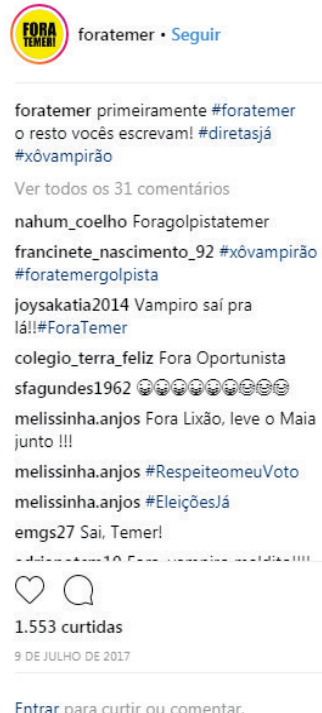

Entrar para curtir ou comentar.

Imagem 1: Michel Temer após o impeachment/golpe da ex-presidenta Dilma Rousseff

Fonte: Fora Temer (2017a)

Nesta montagem verbo-visual (Imagem 1), recortada no ano de 2017, da página do Instagram que, "coincidentemente", possui o nome do bordão "Foratemer", podemos observar a montagem sob uma foto de Temer, bem como comentários ao lado, por meio dos quais fica perceptível a insatisfação dos seguidores desta página com o governo. A montagem ainda contém a remissão a uma imagem clássica de vampiro, com os dentes caninos à mostra, os quais, nas histórias vampirescas, são os responsáveis pelo sugar de sangue das vítimas - sangue, uma energia vital - e sacear sua sede infinita a manter-se pelo eterno, juntamente com os escritos: "Primeiramente, Fora Temer e Diretas Já". Tem-se, nessa montagem, diversas questões discursivas e derrisórias caras a uma compreensão da comunicação política como fenômeno discursivo de linguagem.

Ao relacionarmos com a historicidade dos discursos da montagem, tornou-se muito comum em diversos grupos sociais à época e, mesmo em tom de deboche, dizer a pequena frase "primeiramente, Fora Temer" e, em seguida, dar a sequência ao que se iria falar. Tal gesto cenográfico-verbal ganhou os entornos da realidade e não somente das redes virtuais ao fazer valer um tom derrisório para dizer que, explícita e implicitamente, não há, para essa região de mobilização de discursos - ligada aos sujeitos que se colocam como anti-Temer e, portanto, anti aquele que usurpa o poder constituído -, possibilidades de interações sociais possíveis sem retirar o então presidente brasileiro, com o usurpador de volta a outro lugar, que não aquele que ele está a usurpar.

Mais ainda, com a conjugação da imagem aos enunciados ditos, a energia vital da nação está representada na derrisória caricatura e, para se viver, primeiramente, é preciso afastar essa figura derrisoriamente transformada em vampiro na foto-montagem, representando o lugar usurpado, aquele que suga e usurpa o poder neste lugar. Além disso, o retorno do slogan político "Diretas 
Já", clássico das palavras de ordem de um movimento dos anos 1980, do Brasil, em que se pedia a redemocratização depois de mais de vinte anos de ditadura militar, alçada ao poder a partir de um golpe, em $1^{\circ}$ de abril de 1964, tem-se uma clara associação, de forma derrisória pela montagem, em verbo e visual, de ligar Temer a um ser político, metaforseado em Vampiro na montagem, a um golpe, um gesto que nos traz à memória histórico-social outros golpes e um sujeito político anti-democrático. Assim, é necessário, portanto, que ele renuncie e abra espaço para a decisão do sufrágio universal; que abra, nesse processo discursivo, espaço para uma reação ao golpe do qual este sujeito fez e faz parte.

A montagem verbo-visual, como movimento de zombaria de vertente da cultura popular e política, dantes dado nas ruas, como no movimento Diretas Já!, dos anos 1980, atualmente se reconfigura nas esferas da cultura digital, aludindo-nos a dizer que, em todo ponto discursivo, não há um especificamente dentro e um fora das redes, como bem nos lembra Marie-Anne Paveau (2021).

No entanto, Michel Temer e Vampiro não são associação nova. Ele é comparado a um vampiro nas redes sociais analógicas e virtuais desde o começo da sua carreira política, encejado de lendas sobre suposta adesão às correntes místicas de satanismo, por ter certa semelhança com o ator Béla Lugosi e mais semelhança ainda com Gary Oldman, ambos na interpretação cinematográfica da personagem Drácula, inspirada nas histórias de Bram Stoker, respectivamente, em 1931 e 1992, como podemos observar nas imagens inseridas a seguir:

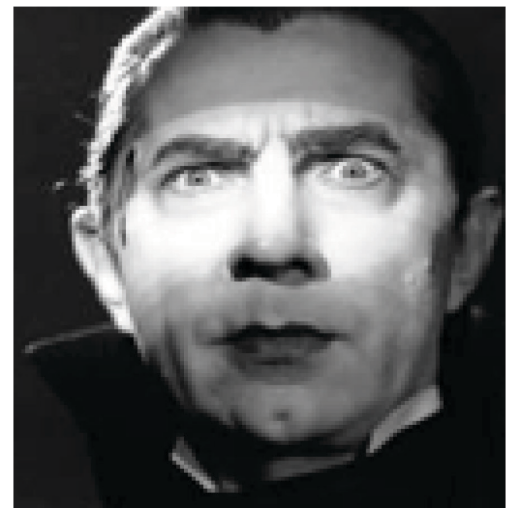

Imagem 2: Béla Lugosi como Drácula de Bram Stoke, 1931 Fonte: Nolla (2021)

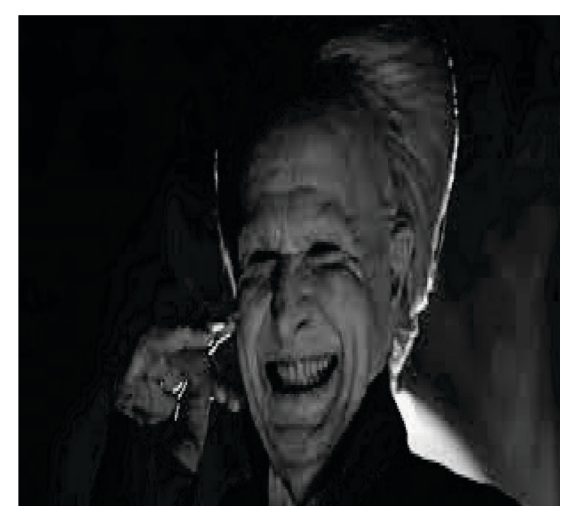

Imagem 3: Gary Oldman como Drácula de Bram Stoke, 1992

Fonte: Blume (2016)

Ao relacionar com o discurso derrisório, o riso e escárnio mais agressivos ficam por conta da comparação ao utilizar os dentes de vampiro em sua própria foto, a qual remete que Temer é que irá sugar e atacar, na jugular, os pescoços da nação, visto que o vampiro é um ser mitológico, mas que só sobrevive ao ser alimentado da essência de outras criaturas e com o ressalte em seus longos caninos que são justamente as armas que nos sugarão. Portanto, fruto da usurpa, a chegada ao poder de Michel Temer é compreendida, derrisoriamente, como a figura meio humana, meio animalesca, meio morta, meio viva. Figura a atacar com seu poder o outrora poder constituído pelo desejo de uma sociedade, em uma democracia, ainda que liberal-burguesa, que foi manifestado pelos votos e eleição, em 2014, de Dilma Rousseff. Esta, por sua vez, tinha no usurpador a confiança de um vicepresidente, ou ao menos demonstrava isso em público. Dita confiança que o usurpador não respeitou, e sim a atacou com seus poderes maléficos, sendo transformado na figura de um Vampiro. Há, sem dúvida, a quebra de confiança de parte da população e uma quebra de confiança, vampirizada e usurpadora no campo de atuação dos discursos políticos, a qual a montagem encenou de forma precisa.

Evidentemente, por se tratar de uma narrativa para o golpe ou impeachement que envolve mitos, folclores e forças sobrenaturais, a conspiração real em relação à usurpa de poder deve ser lida discursivamente, tanto no dicurso verbal quanto virtual, por meio dos quais os processos de significação dão um tema na formas derrisórias de ataque ao então sujeito titular da presidência naquele ano de 2017. 

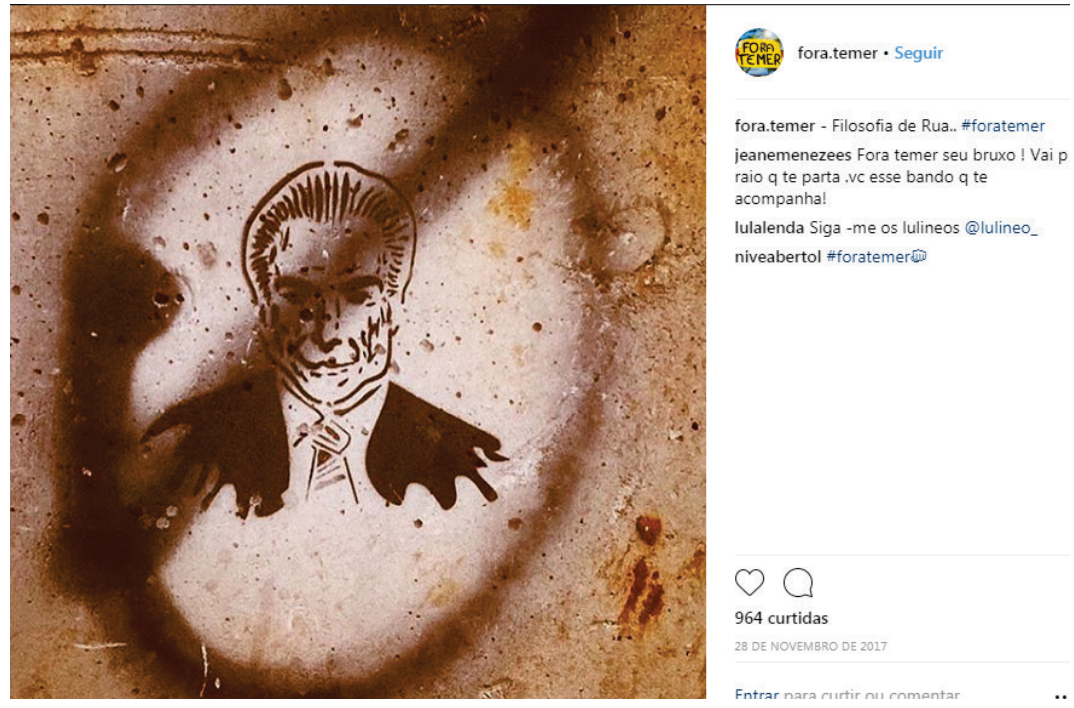

Imagem 4: Michel Temer após o golpe/impeachment da Dilma Rousseff

Fonte: Fora Temer (2017b)

Já por nesta segunda montagem verbo-visual (Imagem 4), que também se refere aos acontecimentos históricos em que se suscederam ao processo de golpe/impeachment, mas aqui tratado claramente como golpe contra a ex-presidenta Dilma Rousseff, em agosto de 2016, por meio do qual, seu vice-presidente, Michel Temer, assumiu o poder, compreende-se o prosseguimento entre o oficial, no qual as Instituições brasileiras que se postam como democráticas a declarar que tudo faz parte de um rito normal e legal, e o oficioso, por meio da qual se alega um claro golpe, nas narrativas entre impeachment/golpe em disputa nos imaginários das forças políticas brasileiras e mundiais ${ }^{5}$.

Temer assume como um gestor de transição, como alguém que reestabeleceria as "pontes" entre os diversos poderes governamentais e a sociedade civil para um "futuro" melhor ao país. Era para ser um governo temporário, porém, passou a ser permanente. Assim, iniciam-se diversas manifestações que não repercutiram apenas nas ruas, mas em todas as redes sociais, com a utilização de hashtag e páginas com o nome do bordão "Fora Temer", letras de músicas etc., sendo um período que desencadeou uma série de montagens e charges.

Na montagem 2 (Imagem 3), ainda, que foi publicada no dia 28 de novembro de 2017, notamos os comentários de pessoas que curtem a página e a própria legenda da foto "Filosofia de rua... \#foratemer", mais a imagem de Temer, bastante assemelhadas ainda às clássicas personagens de Vampiros de cinema (Imagens 3 e 4), envolta em um círculo riscado ao meio, lembrando uma placa de trânsito em que se proibe alguma ação - do tipo estacionar, por exemplo -, e como se fosse uma pixação de parede. Derrisoriamente, além da zombaria à representação de ser satânica/satanista, bruxo como quer o dizer ao lado da imagem, vampiresca, pela semelhança às notórias imagens de Dráculas e usurpadora que se quer apresentar, com os diversos \#foratemer, mandando-o ir para o raio que o parta, como uma árvore alvejada por um raio na natureza, busca-se, igualmente, dar um aspecto imagético nos discursos produzidos por esse tipo de montagem de que a "ideia" de um fora Temer, usurpador, indesejado, traidor toma as ruas e se transforma em uma filosofia de rua, em um sentido genérico de saber que se propaga entre a sociedade e as diversas classes, tal qual quer os efeitos de sentidos buscados ao se postar um "coro" discursivo por meio do dizer "filosofia de rua...\#foratemer. Dito de outro modo, nas ruas, na insurreição que se deve tomar pelas ruas, por meio desse saber, vamos - e o discurso imagético nos sugere esse sentido - cancelar, proibir o usurpador. Uma vez mais, a zombaria mais agressiva, direta e que busca uma mobilização discursiva mais devastadora, torna-se possível no visual desta postagem, criando-nos a evidência de que aquela montagem é algo já presente nas ruas, um saber das ruas, em que todos veem Temer como um usurpador a ser retirado pela

${ }^{5}$ Sobre isso, ver o trabalho de Possenti (2016). E sobre isso, ainda, atentem-se, leitores, às exposições das diversas conversas entre membros da força-tarefa do Ministério Público Federal, de Curitiba, liderada por Deltan Dallagnol, e o então juiz Sérgio Moro, também da Justiça Federal, de Curitiba, as quais mostram múltiplas articulações políticas e não somente jurídicas que corroboraram a queda da ex-presidente Dilma Rousseff e a condenação, prisão e perda de direitos políticos do ex-presidente Luiz Inácio Lula da Silva. O caso se tornou público como Vazalato depois de uma série de reportagens iniciadas pela mídia Intercept, que obteve as mensagens por meio de um grupo de hackers e, mais recentemente, pelo levantamento de sigilo dessas mensagens feitas pelo Supremo Tribunal Federal brasileiro. 
sociedade.

Todavia, é no carnaval de 2018 que vem o grande "golpe" verbo-visual mais marcado para Temer. É na maior festa popular que a charge de Temer presidente vampiro ganha destaque, associado a um enredo recheado de críticas trabalhistas, políticas, entre outras, ao ator político ${ }^{6}$, como veremos no segundo percurso: Temer, usurpador autoritário.
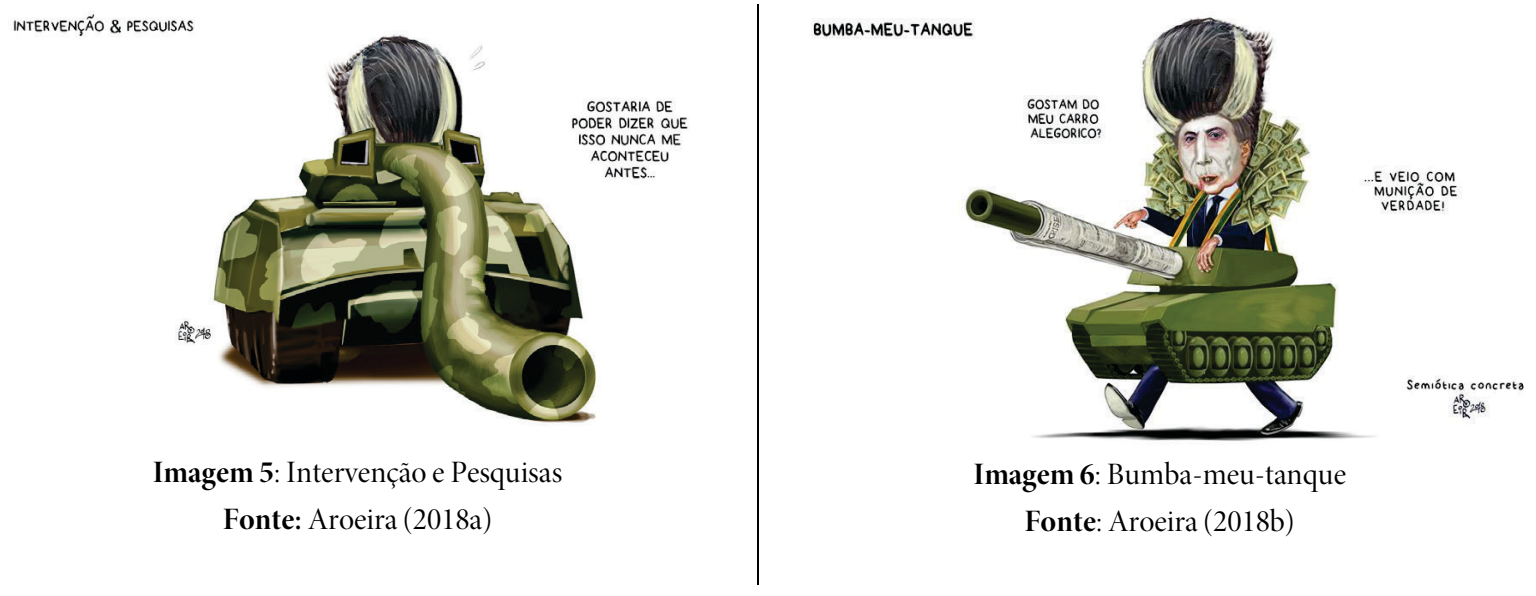

No acontecimento do carnaval de 2018, a escola de samba Paraíso de Tuiuti, do Rio de Janeiro, apresentou uma crítica bastante direta ao governo federal sob comando de Temer, relembrando, entre outras coisas, a escravidão que, exatamente naquele ano, completava 130 anos desde o fim da exploração humana, evidentemente apenas como marco histórico "legal", uma vez que exploração humana análoga à escravidão, bem como todos os preconceitos étnicos-raciais persistem no Brasil e no mundo. Mais ainda, outras alas foram representadas com diversos temas, como: desigualdade social, exploração do trabalho rural e em oficinas industriais, trabalho infantil e a denúncia sobre a recente reforma trabalhista. Em um dos carros alegóricos, contou-se com a presença de um personagem que representava um "presidente vampiro", que remete diretamente a Michel Temer e a seu governo, como vemos na Imagem 7 abaixo.

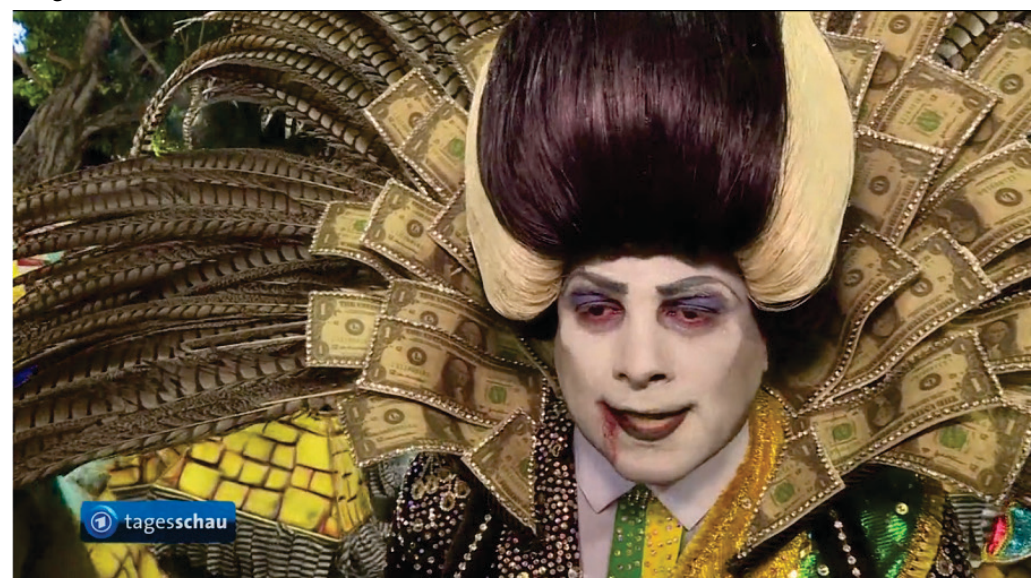

Imagem 7: Leo Morais representando um Vampiro, alusivo a Temer, na escola Paraíso Tuiuti, fevereiro de 2018

Fonte: Redação (2018)

A repercussão sobre o enredo da escola gerou uma euforia e raiva em algumas pessoas, como o impedimento para esse personagem sobre a utilização da faixa presidencial no desfile das campeãs, visto que a escola se classificou em segundo lugar e teve o direito ao segundo desfile.

\footnotetext{
${ }^{6}$ Vale ressaltar que alguns artistas e cantores criaram uma música "Xô Vampirão", que pedia a saída de Michel Temer da presidência. Além dessa, os cantores do gênero de rap PrimeiraMente criaram uma música chamada Fora Temer.
} 
Temer $^{7}$ não demonstrou incômodo em público. Quando questionado, só soube responder "que a sátira faz parte da cultura brasileira e que, nos momentos de maior transformação política, o humor é sempre utilizado." Pelo enredo escolhido, a escola foi impulsionada rapidamente em todas as redes sociais, ocasionando uma série de discursos em gêneros verbo-visuais a respeito desse tema em relação ao presidente da época, Michel Temer.

Sendo assim, na charge 1 (Imagem 5), a memória derrisória vem acompanhada da referência ao Vampiro-presidente da escola Tuiuti mais os eventos que se sucederam em um outro acontecimento, logo na sequência ao carnaval, qual seja, uma intervenção Federal, ainda em fevereiro de 2018, por meio de uma GLO (Lei de garantia da ordem), comandada pelo exército, que não tinha precedente desde a extinta ditadura civil-militar (1964-1985), que trouxe à tona atos e efeitos de intervir e indica alguma mediação da situação adversa. Por isso, a figura representando um militar na charge, quando questiona ao Vampiro Temer/Tuiuti sobre qual área do Rio de Janeiro deveria intervir, a resposta da personagem Temer é "Paraíso de Tuiuti", devido ao incômodo da situação do carnaval.

Neste sentido, se tomarmos que o discurso derrisório no humor dessa charge constrói um processo de sentidos de zombaria e escárnio agressivos na comunicação política contra Temer e seu governo usurpador, que se correlaciona ao ato de esse governo fazer uma intervenção grave, temos então que o humor agressivo cumpre sua regularidade e dispersão histórica no sentido de ir além de uma simples troça ou cometário jocoso; ele vai ao âmago de uma reverberação discurisva. Com isso, é possível inferir ao menos uma zombaria mais agressiva.

Já na charge 2 (Imagem 6), retrata-se a diferença de "carros". No carro alegórico, foi representada a maneira pela qual as pessoas estão insatisfeitas com seu "desgoverno", o que levou o presidente a uma irritação diante da derrisão discursiva pelo discurso imagético contra a escola de samba, como uma espécie de parte pelo todo, porém, que se entende, de modo análogo, a partir da intervenção, em uma investida contra toda sociedade, a começar pelo Rio de Janeiro, local em que primeiro se desenrolou a zombaria mais agressiva ao ex-presidente. Ainda, na imagem da charge, o Temer está fantasiado em cima de um carro de combate, que representa estar preparado por conter poderosas armas que servem tanto para atacar quanto para se defender. Nas rodas, é possível perceber o símbolo da Rede Globo, visto que o desfile constrangeu os narradores da emissora, deixando-a em saia justa. Esta é uma emissora historicamente conservadora e governista por seus interesses, inclusive em governos ditatoriais, e ao não reproduzir algumas passagens da escola no reprise, pode-se inferir que a Rede Globo, apoiada ao tanque de guerra de Michel Temer, também se fere diante de uma crítica mais mordaz, feita na derrisão da charge. Charge que nos revela, então, um segundo momento de percurso de Temer Vampiro e usurpador, o usurpador autoritário.

\section{QUESTÕES FINAIS}

Com a baixa modernidade, o ambiente digital viabiliza diversas ferramentas e as torna acessíveis ao público, com matérias de diferentes conteúdos e mais dinâmicos. As montagens verbo-visuais e charges aqui analisadas são utilizadas por meio de frases e situações cotidianas que circulam depois de algum acontecimento histórico marcante, tornado discursivo pelo próprio embate nas esferas de comunicação digitais, que, por sua vez, ao se juntarem, trazem um significado humorístico mais agressivo, seja de uma crítica social, seja de política em objeto de uma comunicação discursiva verbo-visual.

Para revelar a construção de sentido nesses gêneros, seja no tom humoristíco, seja no tom crítico, é preciso levar em consideração os personagens presentes, a interação do observador e a composição das imagens, desde o momento da produção até a interferência do leitor, com sua cultura e contexto social. Esses aspectos auxiliam na análise das ideologias específicas dos discursos em gêneros verbo-visuais, sendo notórios as críticas e o humor.

Nesse sentido, a figura política de Michel Temer, político de baixa popularidade que chegou ao poder, segundo alguns

${ }^{7}$ Porém, comenta-se em análises políticas próximas aos íntimos e outros cicerones do ex-presidente que ele ficou irritado e insatisfeito ao ter sido representado pela escola daquela maneira, pois não esperava a repercussão causada, o que, se for verdade, demonstra que o humor derrisório, com sua agressividade, atingiu em cheio o objetivo. 
posicionamentos, de forma ilegítima, por meio de um processo de afastamento político da então presidenta, Dilma Rousseff, inclusive com a pecha de traidor, ou, melhor, de um usurpador, algo que tentamos tematizar em um percurso neste texto, torna-se um objeto central e bastante derrisório.

Todavia, não só por isso se tornou alvo, mas também por sua própria contribuição discursiva, uma vez que, por diversas vezes, esse político brasileiro cometeu gafes, fez discursos negacionistas, críticas sociais inadequadas para qualquer cidadão, sobretudo para um presidente. Portanto, pode se dizer que ele contribuiu de forma decisiva para que fosse alvo de discursos derrisórios. Dessa forma, ainda, por ser um recurso discursivo que circula nos meios virtuais, principalmente, as montagens e charges lançam mão de uma série de expedientes, tanto verbais como não verbais e/ou sincréticos. Para sua compreensão, é preciso que haja um saber partilhado no contexto social. Mesmo se esse conhecimento for um pouco vago, é possível perceber representações discursivas que divergem entre si e resultam em distintas interpretações e não tão completas sobre o que ele quer representar.

É justamente nessa perspectiva de um outro pouco compartilhado pelos saberes que o conceito de derrisão discursiva aparece, pois o sentido de zombaria, de troça do outro, não necessariamente se faz apenas na relação eu e outro de forma transparente, $o$ que significa dizer que muitas vezes o outro é bastante distorcido, sobretudo nos discursos derrisórios que lançam recursos diversos para descaracterizar o outro, zombá-lo.

Evidentemente, não se trata de um artigo que visa a esgotar todos os dados, mas, de certa forma, tentou-se jogar luz a um fenômeno de linguagem e de discurso por meio da tematização de dois pequenos percursos em que se mantêm a figura de um político usurpador em destaque. Com efeito, a derrisão discursiva no mundo digital, sobretudo em seu viés de atuação política, compreende bem efeitos de humor mais agressivo e que causam reverberações sociais, principalmente porque atualmente o universo digital está em grande parte das vidas das pessoas, mesmo ao se posicionarem em acontecimentos e conjunturas históricas e sociais que se correlacionam fora a essa cultural digital, que são, a bem da verdade, um todo da existência linguageira da sociedade.

\section{REFERÊNCIAS}

AROEIRA, Renato. Intervenção e Pesquisas. Humor político. 4 mar. 2018 . Disponivel em: https://www.humorpolitico.com.br/aroeira/intervencao-e-pesquisas/. Acesso em: 17 jun. 2021.

AROEIRA, Renato. Bumba-meu-tanque. Humor político. 18 fev. 2018b. Disponível em: https://www.humorpolitico.com.br/page/69/?ref=politico.com.br. Acesso em: 17 jun. 2021.

BARONAS, R. L. Derrisão: um caso de heterogeneidade dissimulada. Polifonia, Cuiabá, v. 10, n. 10, p. 99-111, 2005.

BARONAS, R. L. Notas breves sobre a derrisão no gênero do discurso fotografia. Polifonia, Cuiabá, v. 8, n.8, 2004.

BARONAS, R. L. Textualizações derrisórias do político: notas sobre um caso de heterogeneidade dissimulada. In: BARONAS, R. L.; COX, M. I. P.; DIAS, M. F. Estudos em ciências da linguagem: diálogos, fronteiras, limites. Cáceres: Editora Unemat, 2008. p. 20-33.

BARONAS, R. L.; KOSCIURESKI, M. B. S.. Observações sobre a textualização do "sic" no discurso político: marcas de derrisão. In: NAVARRO, P. (org.) Estudos do texto e do discurso. São Carlos, Claraluz, 2006. p. 71-83

BAKHTIN, M. Estética da criação verbal. São Paulo: Martins Fontes, 1997.

BLUME, Bill. Six Worst Draculas: Bram Stoker's Dracula. Bill Blume. 24 ou. 2016. Disponível em: https://billblume.wordpress.com/2016/10/24/six-worst-draculas-bram-stokers-dracula/. Acesso em: 17 jun. 2021. 
BONNAFOUS, S. Sobre o bom uso da derrisão em J.M.L e Pen. Trad. Maria do Rosário Gregolin e Fábio César Montanheiro. In: GREGOLIN. M.R. (org.). Discurso e mídia: a cultura do espetáculo. São Carlos, SP: Claraluz, 2003. p. 132149

CHARAUDEAU, P..; MAINGUENEAU, D. Dicionário de análise do discurso. São Paulo: Editora Contexto, 2004.

COURTINE, J.-J. Análise do discurso político. São Carlos, SP: EdUFSCar, 2009.

FONTANA, Mónica. G. Z. Argu(meme)ntando Argumentação, discurso digital e modos de dizer. [Apresentação em Power point]. In: Seminário Internacional de Estudos sobre Discurso e Argumentação (III SEDiAr), 3., Universidade Federal de Sergipe. São Cristóvão, 2016. Disponível em: http://octeventos.com/sediar/programacao-minicursos.php. Acesso em: 4 fev. 2018.

FORA TEMER. Instagram. @foratemer. 25 mai. 2017a. Disponível em: https://www.instagram.com/p/BWVtbtjKqo/?utm_medium=copy_link. Acesso em: 17 jun. 2021.

FORA TEMER. Instagram. @fora.temer. 2017b. Disponível em: https://www.instagram.com/fora.temer/. Acesso: 17 jun. 2021.

LIMA, R. R. Aforização oitocentista: espaço de discursividade da Revista Illustrada. 2017. Tese (doutorado) - Universidade Federal de São Carlos, São Carlos. São Carlos, SP, 2017.

MAINGUENEAU, D. Análise de textos de comunicação. São Paulo: Cortez, 2008.

MAINGUENEAU, D. Cenas da enunciação. Curitiba: Criar Edições, 2006.

MAINGUENEAU, D. Discurso e análise do discurso. São Paulo: Parábola Editorial, 2015.

NOLLA, Thiago. 'Drácula', estrelado por Bela Lugosi completa 90 anos; Confira 10 curiosidades sobre o clássico e influente filme. Cinepop. 14 fe. 2021. Disponível em: https://cinepop.com.br/dracula-estrelado-por-bela-lugosi-completa-90-anosconfira-10-curiosidades-sobre-o-classico-e-influente-filme-283597/. Acesso em: 25 fev. 2021.

PAVEAU, M.-A. Análise do discurso digital: dicionário das formas e das práticas. Campinas: Pontes Editores, 2021.

PÊCHEUX, M. Discurso: estrutura ou acontecimento. Campinas, SP: Pontes, 2008.

POSSENTI. Diferenças condensadas em palavras.Revista de Estudos da Linguagem, Belo Horizonte, v.24, n.3, p. 1075-1099, set-dez, 2016. Disponível em: http://dx.doi.org/10.17851/2237-2083.24.3.1075-1099. Acesso em: 25 mar. 2021.

REDAÇÃO. Carnaval do Rio: Temer como 'vampiro corrupto' vira destaque no principal. 14 fev. 2018. Operamundi. Disponível em: https://operamundi.uol.com.br/politica-e-economia/48867/carnaval-do-rio-temer-como-vampiro-corruptovira-destaque-no-principal-telejornal-da-alemanha. Acesso em: 17 jun. 2021.

\section{(1) $\circledast \circledast$}

Recebido em 23/02/2021. Aceito em 10/04/2021. 